\title{
RECURSOS LÍTICOS EN EL CENTRO-OESTE DE LA PROVINCIA DE SANTA CRUZ: UNA APROXIMACIÓN DESDE LA PETROGRAFÍA
}

\author{
Silvana Espinosa*, Gisela Cassiodoro ${ }^{* *}$, Josefina Flores Coni ${ }^{* * *}$, \\ Agustín Agnolin ${ }^{* * * *}$ y Pedro Tiberi ${ }^{* * * * *}$
}

Fecha de recepción: 23 de diciembre de 2020

Fecha de aceptación: 20 de abril de 2021

\section{RESUMEN}

Las distintas investigaciones arqueológicas que se vienen desarrollando desde hace más de veinticinco años en las cuencas lacustres cordilleranas y pericordilleranas de la provincia de Santa Cruz han permitido tener un conocimiento amplio de la base regional de recursos líticos. Este trabajo presenta los primeros resultados sobre sus determinaciones microscópicas. En esta oportunidad, se evalúa la variabilidad geológica y arqueológica de rocas asignadas macroscópicamente como basaltos, las cuales resultan más heterogéneas de lo inicialmente planteado. Asimismo, la localización y determinación de puntos singulares de disponibilidad de basaltos y tobas a lo largo de toda la región resultan indicadores adecuados para establecer posibles rutas de circulación de estas materias primas. En consecuencia, se analiza el alcance reducido de esta circulación dentro de cada cuenca.

Palabras clave: basalto - tobas - disponibilidad y heterogeneidad - cortes delgados Patagonia austral

\footnotetext{
* Centro de Investigación y Transferencia SANTA CRUZ, Consejo Nacional de Investigaciones Científicas y Técnicas, Universidad Nacional de la Patagonia Austral, Universidad Tecnológica Nacional. E-mail: silvanaespinosa@conicet.gov.ar

** Consejo Nacional de Investigaciones Científicas y Técnicas, Universidad de Buenos Aires, Instituto Nacional de Antropología y Pensamiento Latinoamericano. E-mail: gcassio@hotmail.com

*** Consejo Nacional de Investigaciones Científicas y Técnicas, Instituto Nacional de Antropología y Pensamiento Latinoamericano. E-mail: josefinafloresconi@gmail.com

**** Consejo Nacional de Investigaciones Científicas y Técnicas, Instituto Nacional de Antropología y Pensamiento Latinoamericano. E-mail: agusagnolin@yahoo.com.ar

***** Universidad Nacional de la Patagonia Austral, Instituto de Ciencias del Ambiente, Sustentabilidad y Recursos Naturales. E-mail: pedro.tiberi@gmail.com
} 
Relaciones de la Sociedad Argentina de Antropología 46 (1), enero-junio 2021: 291-311

\section{LITHIC RESOURCES IN CENTRAL-WEST SANTA CRUZ PROVINCE: A PETROGRAPHIC APPROACH}

\section{ABSTRACT}

More than 25 years of ongoing archaeological research in the Andean and peri-Andean lake basins of the province of Santa Cruz have provided an extensive understanding of the regional availability of lithic raw materials. The first data based on microscopic determinations carried out with this record are presented. In this study, the geological and archaeological variability of rocks macroscopically identified as basalt is assessed: results show that they are more heterogeneous than what it was initially proposed. Furthermore, the location and determination of singular points of basalt and tuff availability throughout the region are suitable indicators to establish possible circulation routes of these raw materials. Consequently, a reduced scope of this circulation is analyzed within each basin.

Keywords: basalt - tuff-availability and heterogeneity - petrographic thin sections - South Patagonia

\section{INTRODUCCIÓN}

Las investigaciones arqueológicas desarrolladas en el centro-oeste de la provincia de Santa Cruz (Aschero et al. 2005; Guraieb et al. 2006; Espinosa et al. 2009; Cassiodoro et al. 2015; entre otros) han considerado la disponibilidad y accesibilidad de las materias primas líticas como uno de los condicionantes para explicar la variabilidad en las estrategias tecnológicas (Bamforth 1986, 1990; Andrefsky 1994). Necesariamente, para entender el aprovisionamiento de materias primas y la producción de los artefactos es fundamental establecer la estructura de la base regional de recursos minerales (Ericson 1984). Esto implica considerar la localización y la forma en que se presentan en la naturaleza las distintas materias primas, ya sea en fuentes primarias o secundarias (Nami 1992), y la distancia respecto de los lugares donde será utilizada (Bamforth 1990; Andrefsky 1994; Civalero 1999; Beck et al. 2002; Thacker 2006, entre otros).

Por lo tanto, desde los inicios de las investigaciones en la Pampa del Asador y las cuencas lacustres San Martín-Tar, Cardiel, Strobel, Guitarra, Belgrano-Burmeister y Salitroso (figura 1) se ha focalizado en caracterizar los diferentes depósitos de materia prima lítica factibles de ser utilizados por las poblaciones cazadoras-recolectoras (Espinosa y Goñi 1999; Belardi et al. 2015; Cassiodoro et al. 2015; Espinosa et al. 2015; Agnolin et al. 2018). Esto ha llevado a establecer una abundante oferta de estos recursos en la región, favorecida por su ubicación geográfica (Ramos 1982). Las principales canteras arqueológicas registradas hasta el momento son a) Pampa del Asador (Espinosa y Goñi 1999) -fuente de obsidiana, basalto y sílices-; b) distintos sectores del lago Cardiel con disponibilidad de limolita (Belardi et al. 2015), tobas, basaltos y rocas silíceas (Agnolin et al. 2018); y c) la cuenca lacustre San Martín-Tar donde aflora toba silicificada verde (Espinosa et al. 2009) y basaltos (Espinosa y Belardi 2016). Asimismo, se han registrado diferentes depósitos de rocas silíceas y basalto en las cuencas de los lagos Posadas (Guraieb 1998) y Belgrano-Burmeister (Aschero et al. 1992). No obstante, el registro arqueológico da cuenta de que la variedad de rocas utilizadas por las poblaciones cazadoras a lo largo del Holoceno es mucho mayor (Cassiodoro 2011; Agnolin 2019; Flores Coni 2019).

Como se observa, la composición litológica permite plantear la existencia de una base regional de recursos minerales amplia y variable. En el conjunto de las rocas disponibles, se destacan los basaltos por tener una extensa dispersión natural y haber sido utilizados como materia prima en todos los sectores de la región de estudio mencionados. Asimismo, se detectó que el 
conjunto de rocas generalmente clasificadas como basaltos presentaba una gran variabilidad en sus características macroscópicas, sugiriendo que esta categoría resultaba excesivamente amplia y ocultaba litologías diferentes. Efectivamente, tanto trabajos previos geológicos (Ramos 1982) como arqueológicos (Belardi y Carballo Marina 2005; Guraieb 2012; Espinosa et al. 2019) reconocen dicha variabilidad.

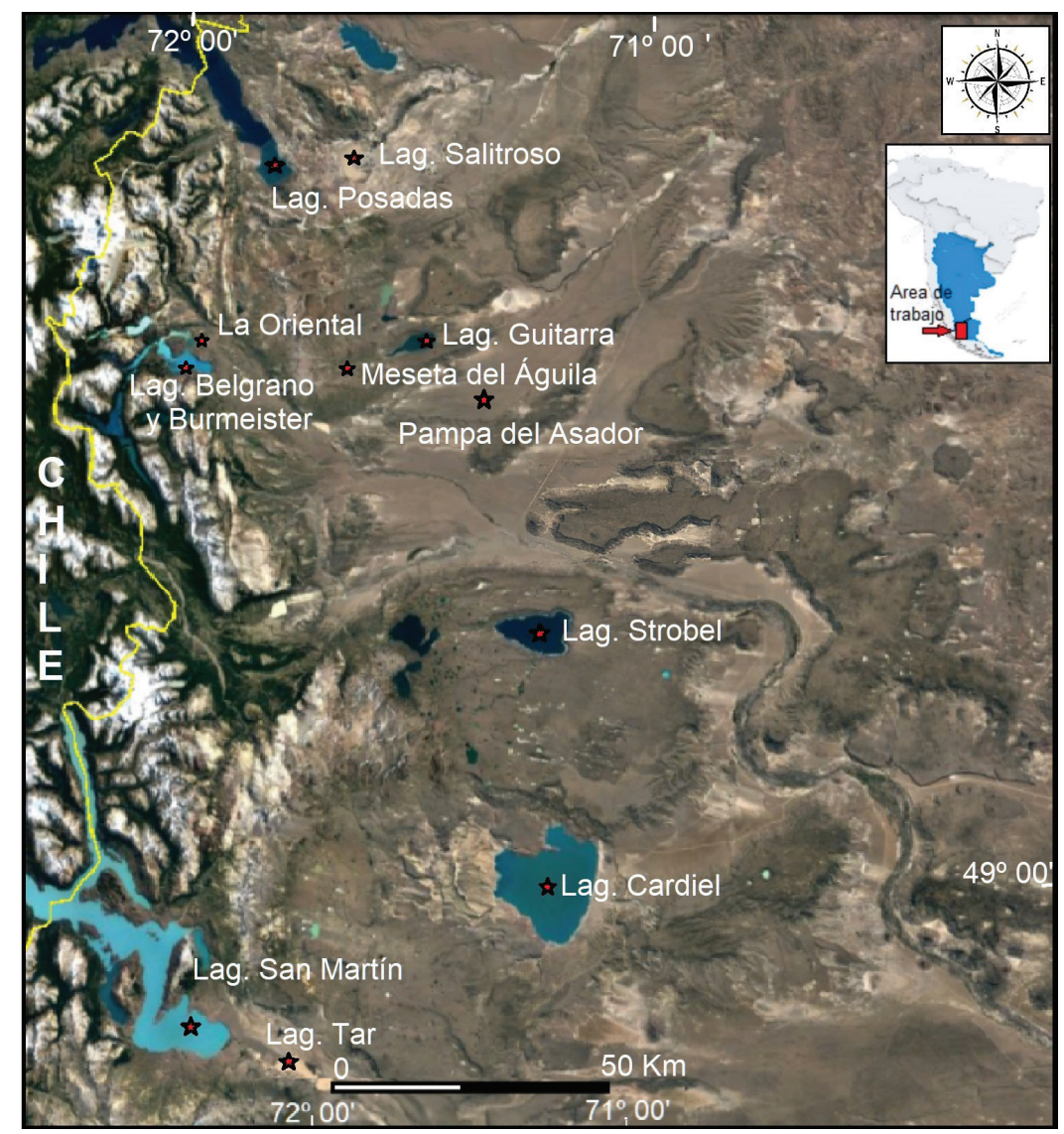

Figura 1. Región de estudio, cuencas lacustres, pampas y mesetas analizadas

En función de ello nos preguntamos si todas las rocas clasificadas como basalto efectivamente lo son, si las clases de basaltos registradas macroscópicamente presentan las mismas características petrográficas, si es factible especificar las variedades de basaltos disponibles en cada cuenca y qué implicancias podría tener esto en el desarrollo de las estrategias tecnológicas líticas en el pasado. Por lo tanto, dentro de los objetivos generales de las investigaciones tecnológicas en curso, los cuales buscan ampliar el conocimiento de la base regional de recursos minerales de Pampa del Asador y las cuencas lacustres San Martín-Tar, Cardiel, Strobel, Guitarra, Belgrano-Burmeister y Salitroso (Espinosa et al. 2016), se ha puesto foco en profundizar el conocimiento de la disponibilidad y distribución de los basaltos (Espinosa et al. 2019). Para ello, se efectuaron nuevos relevamientos en el campo y se comprobó que la determinación macroscópica como basaltos de algunos artefactos enmascaraba variabilidad. Esto llevó a la realización de análisis petrográficos tanto de muestras que fueron catalogadas como basalto, pero presentan diferencias macroscópicas, como de aquellas cuya clasificación como tales resultaba imprecisa. 
De modo que el objetivo específico de este trabajo es presentar la información sobre los nuevos relevamientos de campo y las interpretaciones de los cortes delgados realizados a muestras de mano geológicas y arqueológicas de la región de estudio. Esto resulta un aporte para comprender la utilización de un recurso lítico en particular por parte de las poblaciones cazadoras-recolectoras en una escala macro y mesorregional.

\section{REGIÓN DE ESTUDIO}

La región bajo estudio comprende, desde el norte, las cuencas de los lagos Salitroso-Posadas, Belgrano-Burmeister y Guitarra hasta la cuenca lacustre San Martín-Tar, al sur; el extremo oeste lo marca el límite con Chile y hacia el este, el final de las estribaciones correspondientes a las mesetas Cardiel Chico y Pampa del Asador (figura 1). En las cuencas lacustres San Martín-Tar, Cardiel, Belgrano-Burmeister y Salitroso-Posadas se han realizado estudios paleoclimáticos y paleoambientales que permiten establecer la existencia de fluctuaciones ambientales a lo largo del Holoceno (Stine y Stine 1990; Stine 1994; González 1992; Gilli et al. 2001; Bamonte et al. 2013; Quade y Kaplan 2017; Horta et al. 2017, 2019). La tendencia regional señala un creciente incremento de la temperatura y la baja en la humedad, sin embargo, existen diferencias climáticas entre las cuencas. Sobre esta base, resulta de especial interés conocer la disponibilidad de espacios aptos para las ocupaciones humanas y el acceso a los recursos minerales.

Metodológicamente, la región ha sido segmentada en sectores bajos (100 a 400 m s.n.m.), como las cuencas de los lagos Salitroso-Posadas, Cardiel, San Martín-Tar, y sectores altos (por sobre los 800 m s.n.m.), representados por la cuenca lacustre Belgrano-Burmeister, la Pampa del Asador, la meseta del Águila y las mesetas de los lagos Guitarra, Strobel y Cardiel Chico. Esta variabilidad altitudinal y de características ambientales diferentes y fluctuantes a lo largo del tiempo posee un correlato arqueológico que evidencia diversidad e intensidad de las ocupaciones humanas (Goñi 2000, 2010; Belardi et al. 2013; Cassiodoro et al. 2013).

Asimismo, los estudios tecnológicos realizados en la región han dado cuenta de tal diversidad de utilización de los espacios mencionados (Espinosa 2002; Cassiodoro 2011; Flores Coni 2018; Agnolin 2019). En relación con el manejo de los recursos líticos, se destaca el uso de obsidiana, sílices y basalto -según orden de importancia- en la manufactura de artefactos (Cassiodoro et al. 2015; Espinosa et al. 2015).

\section{LA GEOLOGÍA COMO CONDICIONANTE}

En la región, se pueden identificar características morfológicas generadas por diferentes agentes modeladores del paisaje que actuaron sobre las rocas preexistentes. No obstante, las glaciaciones del Pleistoceno fueron un agente dominante, ya que condicionaron la distribución, selección y clasificación de los materiales que luego fueron empleados en la manufactura lítica. Las aguas de fusión generadas por este agente fueron las principales responsables del labrado del paisaje actual, distribuyendo materiales dentro y fuera del área cordillerana en todas las posiciones topográficas o altitudinales. Los materiales con mayor dureza sobrevivieron a su acción erosiva.

Estas glaciaciones, con sus repetidos avances y retrocesos, y sus aguas de fusión se desplazaron hacia el sector extraandino, por medio de grandes lenguas que circularon entre sectores elevados, de poca pendiente y gran dureza. Estas generaron regiones altas no englazadas como las mesetas basálticas o lávicas Belgrano y Olnie, entre otras, las que, a su vez, actuaron como divisorias de agua. 
En la actualidad, existen remanentes de estas mesetas a modo de grandes parches de ese gran plateau que cubría una extensa área, típica de procesos volcánicos de retroarco (Ramos 1999). La acción de estos hielos operó de forma diferente en las regiones occidental y oriental. En la región oeste (cordillerana), el paisaje está condicionado por una estructura de corrimientos desarrollada en las unidades jurásicas y cretácicas a la que se sobre impuso la actividad glacial. Mientras que en la región oriental extracordillerana se generaron grandes depósitos a modo de planicies con ríos desproporcionados, debido a un menor control estructural, a una litología relativamente homogénea y débil del Cretácico-terciario y a su poca pendiente (Fossa Manzini et al. 1938).

El sector occidental está caracterizado por metasedimentitas de grado metamórfico muy bajo como pizarras, metagrauvacas, cuarzo filitas y cuarcitas altamente deformadas. Las filitas presentan inyecciones de cuarzo que, por momentos, exhiben una textura cristalina granosa. Este cuarzo no resulta apto para la talla. Otro complejo rocoso en el mismo sector lo constituye una unidad volcanoclástica ácida conformada por brechas, tobas, lavas y tobas dacíticas e ignimbritas de colores verdes, blancos hasta rojizos, con marcada disyunción columnar y frecuente silicificación (Riccardi 1971). También se distinguen lavas riolíticas a modo de manto. Estas rocas, a pesar de haber sido devastadas por las glaciaciones, permitieron la disposición de materia prima próxima a sus fuentes, por lo cual, constituyen un recurso lítico importante debido a su grado de silicificación tanto en las lavas como en las arcillitas y tobas.

Al este pueden observarse remanentes de rocas lávicas basálticas, a modo de mantos o cuellos volcánicos, muy compactos, masivos, afaníticos en su mayoría, de aspecto fresco, en algunos casos con presencia de olivina y piroxenos y en otros casos con pasta vítrea, como puede observarse en el sector oriental del lago San Martín. Este material apto para la talla muestra una oferta abundante y de amplia distribución de grandes bloques llevados por agua de fusión fuera de la cuenca del lago. Junto a ello, las tobas, que acompañan a este tipo de roca, se presentan en menor porcentaje sobre los basaltos.

La porción oriental del área de estudio está dominada por una serie de rocas sedimentarias epiclásticas y piroclásticas, en posición casi horizontal, poco compactadas, en parte cementadas por carbonatos, erosionadas por los glaciares, y que asimismo actuaron de base para la depositación de sedimentos de granulometría heterogénea. Esta oferta de material para la talla es muy diversificada. Aquí también, la acción de los glaciares y sus aguas de fusión han destruido las rocas poco consolidadas o cementadas, sobreviviendo solo aquellas que presentan un alto grado de silicificación, las que conformaron cuerpos lávicos dacíticos o piroclásticos desde dacíticos a riolíticos, basaltos vítreos a microporfíricos y tobas silicificadas.

Por lo tanto, debido a esta diversidad de procesos se reconoce la distribución de abundante material basáltico autóctono (neck y coladas) en el sector oeste y de variada composición -tanto alóctona como autóctona- aunque en menor proporción, en el este, aptos para la talla. Es decir, se observa la disponibilidad de basaltos de diversas calidades en cada cuenca lacustre y mesetas estudiadas.

\section{EL PROBLEMA DEL BASALTO EN EL CENTRO-OESTE DE SANTA CRUZ}

Desde el punto de vista geológico, existen las variedades de basalto denominadas Posadas, Belgrano, Cardiel y Strobel (Ramos 1982). Los depósitos secundarios con evidencias de aprovisionamiento en algunos sectores puntuales han sido detallados en otra oportunidad (Espinosa et al. 2019). Sin embargo, aún resta conocer cuáles poseen características óptimas para la talla y, a su vez, cuáles fueron efectivamente utilizados. Por otra parte, la posibilidad de asignar proveniencia a ciertos tipos de basalto permitiría evaluar el transporte de rocas en un contexto en el 
cual la identificación macroscópica se dificulta. A modo de síntesis puede mencionarse que en la cuenca de los lagos Pueyrredón-Posadas-Salitroso, el basalto denominado Posadas se localiza desde las nacientes de los ríos Blanco, Tarde y Furioso (Ramos 1982), al pie de la cordillera. Las investigaciones geológicas en este sector destacan la variabilidad química interna que presentan los mantos basálticos de retroarco (Ramos y Mahlburg Kay 1992; Gorring et al. 1997). Por lo cual, en la misma zona puedan aparecer rocas más básicas (basaltos) junto con aquellas más ácidas (andesitas) (Guraieb 2012). En ese sentido, el área cuenta con análisis petrográficos de muestras arqueológicas del sitio Cerro de los Indios 1 y de una cantera-taller cercana (Guraieb 2012). La muestra de Cerro de los Indios 1 está descripta como un basalto, mientras que la segunda se refiere a un depósito secundario de andesita. Estudios geoquímicos posteriores, realizados por el Dr. Stern, sobre muestras provenientes de ambos sitios determinaron la existencia de $\mathrm{SiO} 2$ en un 62$67 \%$, lo que las ubicaría dentro de las andesitas (Guraieb 2012). Esto llevó a que posteriormente se utilizara esta denominación para conjuntos vinculados con esta cuenca lacustre (Cassiodoro et al. 2004; Méndez et al. 2004; Guraieb 2012; Sacchi et al. 2018).

Acentuando dicha variabilidad, puede mencionarse que se realizaron cortes delgados sobre muestras procedentes de canteras-taller identificadas en la zona de Bajo Caracoles-río Olnie y de la intersección entre la Ruta Nacional 40 y la Pampa del Asador que macroscópicamente resultaban similares al denominado basalto Posadas (Belardi y Carballo Marina 2005). Todas fueron clasificadas como basaltos, aunque la abundante presencia de feldespatos alcalinos y cuarzo permite plantear que químicamente pueden ser rocas intermedias, no básicas. Así, se propuso que la determinación macroscópica del denominado basalto Posadas enmascara una importante variabilidad (Belardi y Carballo Marina 2005; Guraieb 2012).

Por otro lado, en las primeras estribaciones de la meseta del Águila, a $15 \mathrm{~km}$ del lago Belgrano, sobre el arroyo del Águila, se registraron guijarros grandes similares al basalto Posadas (Guraieb 1993). Se observaron, también, guijarros de basalto con otras características macroscópicas en la laguna La Oriental, en inmediata cercanía al lago Belgrano (Guraieb 1993).

Asimismo, en distintos sectores de Pampa del Asador existen guijarros y bloques de basalto en sectores de pavimento del desierto, bordes de lagunas y cicatrices de erosión, considerados como puntos singulares de disponibilidad (Espinosa y Goñi 1999; Cassiodoro et al. 2015). Este basalto posee características macroscópicas diferentes de las observadas en el denominado Posadas. ${ }^{1}$

Del mismo modo, en las márgenes este y sur del lago Cardiel, se observaron grandes bloques de basalto de buena calidad asociados a eventos de talla (Belardi et al. 2003), así como guijarros de menor tamaño en las márgenes noroeste y norte; estos últimos de calidad regular a muy buena (Agnolin et al. 2018).

Finalmente, en sectores altos de la cuenca de los lagos San Martín-Tar se registró un taller y una cantera-taller de basalto. El primero está ubicado en la meseta de San Adolfo, sector norte de la cuenca, y el segundo, en el sitio Laguna El Pajonal 1, en el sector sur (Espinosa y Belardi 2016).

Hasta el momento, no se han registrado canteras en las mesetas de los lagos Strobel y Guitarra, a pesar de formar parte del gran plateau basáltico.

Los análisis de elementos traza de muestras arqueológicas y geológicas de la región refuerzan, por su parte, la premisa sobre la variabilidad de esta roca, con disponibilidad particular en cada área. Así, en el sector sur de la región, se ha podido establecer que los minerales Zr y Ba están restringidos a las muestras geológicas de las cuencas Cardiel y Viedma (al sur de la cuenca Tar San Martín) que, a su vez, comparten elementos con la muestra arqueológica del sitio Manuk 1 (oeste del lago Cardiel). Por otro lado, las muestras geológicas procedentes de la porción norte del área de estudio (Pampa del Asador, meseta del lago Guitarra y cuenca del lago Salitroso-Posadas) comparten otros elementos ( $\mathrm{La}-\mathrm{Yb}$ ), que asimilan las muestras arqueológicas de la meseta del Strobel y cuenca del lago Salitroso con las muestras geológicas de Pampa del Asador (Espinosa et al. 2019). 
Respecto de su utilización como materia prima, el conjunto de artefactos arqueológicos asignados macroscópicamente a basalto no supera el 22\% en la región (Espinosa et al. 2019). La cuenca del lago Salitroso es el sector con los mayores porcentajes $(21,4 \%)$ y la meseta del Strobel, con los menores $(3,43 \%)$. La muestra está principalmente compuesta por desechos de talla y, en menor medida, raederas y filos naturales con rastros complementarios (Espinosa et al. 2019). Sobre un total de 152 sitios arqueológicos que cubren todo el lapso temporal de ocupaciones humanas en los espacios en estudio, se observa que los núcleos están representados en casi todos los conjuntos. No obstante, los sectores con disponibilidad natural de basaltos (cuenca del lago Cardiel) o próximos a ellos (cuenca del lago Salitroso) se destacan con las frecuencias más altas del total de núcleos recuperados (tabla 1).

Tabla 1. Frecuencias y distribución porcentual de núcleos y desechos de talla en el total de la muestra regional, correspondientes a todo el lapso temporal de ocupaciones humanas, y frecuencias y distribución porcentual de núcleos y desechos de talla de basalto utilizados en este trabajo

\begin{tabular}{|c|c|c|c|c|c|c|}
\hline Areas & $\begin{array}{c}\text { Total de } \\
\text { núcleos }\end{array}$ & $\begin{array}{c}\text { Total } \\
\text { núcleos de } \\
\text { basalto }\end{array}$ & $\begin{array}{c}\text { \% de núcleos } \\
\text { de basalto }\end{array}$ & $\begin{array}{c}\text { Total de } \\
\text { desechos de } \\
\text { talla }\end{array}$ & $\begin{array}{c}\text { Total } \\
\text { desechos } \\
\text { de talla de } \\
\text { basalto }\end{array}$ & $\begin{array}{c}\text { \% de } \\
\text { desechos } \\
\text { de talla de } \\
\text { basalto }\end{array}$ \\
\hline Salitroso & 181 & 30 & 16,57 & 4263 & 970 & 22,7 \\
\hline Guitarra & 88 & 9 & 10,23 & 5200 & 738 & 14,2 \\
\hline PDA & 185 & 22 & 11,89 & 6534 & 2154 & 32,9 \\
\hline Belgrano & 46 & 4 & 8,7 & 1498 & 250 & 16,6 \\
\hline Strobel & 13 & - & - & 4969 & 165 & 3,3 \\
\hline Cardiel & 50 & 11 & 22 & 3311 & 648 & 19,5 \\
\hline San Martín-Tar & 65 & 9 & 13,85 & 3976 & 386 & 9,7 \\
\hline Total & 628 & 85 & 13,54 & 29751 & 5311 & 17,8 \\
\hline
\end{tabular}

Referencias: PDA: Pampa del Asador.

\section{CONSIDERACIONES METODOLÓGICAS}

En este trabajo, se utilizó la mesoescala (entre $10-10^{4} \mathrm{~km}^{2}$ ) para la generación de nuevos datos, a la cual se integró la información recopilada en todas las cuencas lacustres y mesetas a través de la macroescala $\left(10^{4}-10^{7} \mathrm{~km}^{2}\right)$ (Dincauze 1987; Delcourt y Delcourt 1992).

En primer lugar, se realizó un relevamiento en terreno con el objetivo de ampliar el conocimiento de la base de recursos líticos de la región y reconocer potenciales fuentes de abastecimiento. A tal fin, se llevaron adelante prospecciones sistemáticas y asistemáticas, tanto en sectores que cuentan con disponibilidad de materias primas (cuencas Cardiel, San Martín-Tar y la Pampa del Asador) como en aquellos en los que aún no se han registrado (meseta Strobel). Dado que se conoce que los depósitos tienden a ser de origen secundario, consecuencia del arrastre fluvioglacial, los relevamientos estuvieron focalizados en bordes de lagunas, cauces de ríos, cicatrices de erosión, etc., ya que allí quedan expuestos guijarros y bloques.

Se consideraron los depósitos con rocas aptas para la talla (básicamente, siguiendo la fractura en cortes frescos in situ) y se consignó su efectivo uso como canteras (Ericson 1984). Asimismo, se recolectaron muestras geológicas en sectores de disponibilidad natural de rocas 
que macroscópicamente pueden ser catalogadas como basaltos. Estos se caracterizan por poseer granulometría gruesa, color oscuro y pasta afanítica.

Con el objetivo de definir las particularidades de estas rocas, se efectuaron análisis petrográficos para establecer sus características litológicas. También se seleccionaron para su estudio muestras que no podían asignarse macroscópicamente a basalto y fueron catalogadas inicialmente como lutitas. Los cortes delgados fueron ejecutados y analizados por el Lic. Del Blanco del Instituto de Recursos Minerales de La Plata. La observación bajo lupa binocular apuntó a señalar rasgos mesoscópicos salientes de cada de una de las muestras analizadas. Asimismo, se determinaron los sectores más adecuados (en función del grado estimado de alteración observado en las muestras) para la realización de los cortes delgados.

\section{RESULTADOS}

Se efectuó un total de 33 cortes delgados de materiales arqueológicos (n: 21) y muestras geológicas (n: 12) de distintos sectores de la región de estudio (tabla 2). Se presenta aquí la información proveniente de la meseta del lago Guitarra, la meseta del Águila, la Pampa del Asador, la meseta del lago Strobel y las cuencas de los lagos San Martín-Tar. La información petrográfica de la cuenca del lago Cardiel ya ha sido presentada en otra oportunidad (Agnolin et al. 2018), pero es incluida en este estudio para enmarcarla en una perspectiva regional. Cabe mencionar que debido a que los conjuntos arqueológicos de basalto de las cuencas de los lagos Belgrano-Burmeister y Salitroso-Posadas presentan homogeneidad macroscópica, por el momento, no se realizaron cortes delgados en muestras de tales áreas. En este trabajo se priorizó a aquellas cuencas que registran variabilidad interna.

Tabla 2. Distribución espacial y procedencia de las muestras geológicas (identificadas con letras minúsculas) y arqueológicas (identificadas con letras mayúsculas) analizadas bajo interpretación petrográfica. Se señalan los sitios y denominación de las muestras mencionadas en el texto

\begin{tabular}{|c|c|c|c|c|}
\hline Área & Muestra geológica & $\mathbf{n}$ & Muestra arqueológica & $\mathbf{n}$ \\
\hline \multirow{3}{*}{$\begin{array}{l}\text { Meseta del lago } \\
\text { Guitarra }\end{array}$} & & & Basalto piroxénico (sitio CG3) (A) & 1 \\
\hline & & & Toba (sitio GUI10) (D) & 1 \\
\hline & ---- & 0 & Arenisca tufítica (sitio GUI10) (E) & 1 \\
\hline Meseta del Águila & Basalto olivínico (b) & 2 & \begin{tabular}{|c|c|}
---- \\
\end{tabular} & 0 \\
\hline \multirow[t]{2}{*}{ Pampa del Asador } & $\begin{array}{l}\text { Basalto piroxénico (Laguna SO del } \\
\text { Cerro Pampa) (a) }\end{array}$ & 1 & $\begin{array}{l}\text { Basalto piroxénico (Laguna SO } \\
\text { Cerro Pampa) (A) }\end{array}$ & 1 \\
\hline & & & $\begin{array}{l}\text { Basalto olivínico (O Cerro Pampa } \\
\text { muestra B17) (B) }\end{array}$ & 1 \\
\hline \multirow{5}{*}{$\begin{array}{l}\text { Meseta del lago } \\
\text { Strobel }\end{array}$} & Basalto olivínico (borde S) (b) & 1 & & \\
\hline & $\begin{array}{l}\text { Basalto microporfírico (sitio K165) } \\
\text { (c) }\end{array}$ & 1 & $\begin{array}{l}\text { Basalto microporfírico (sitio K130) } \\
\text { (C) }\end{array}$ & 2 \\
\hline & Toba (sitio K165) (d) & 1 & $\begin{array}{l}\text { Toba (sitio K11 -muestra H-, sitios } \\
\text { K20 y K26) (D) } \\
\end{array}$ & 5 \\
\hline & Lava (sitio K165) (f) & 1 & ---- & 0 \\
\hline & ---- & 0 & Arenisca tufítica (sitio K55) (E) & 1 \\
\hline
\end{tabular}


(Tabla 2. Continuación)

\begin{tabular}{|c|c|c|c|c|}
\hline Área & Muestra geológica & $\mathbf{n}$ & Muestra arqueológica & $\mathbf{n}$ \\
\hline \multirow[t]{3}{*}{ Cuenca lago Cardiel } & $\begin{array}{l}\text { Basalto microporfírico (muestra } \\
\text { B3 arroyo Bayo) (c) } \\
\text { Basalto olivínico (muestra B6 } \\
\text { arroyo Bayo) (b) }\end{array}$ & 1 & $\begin{array}{l}\text { Basalto piroxénico (muestra B2 } \\
\text { sitio Manuk 1) (A) }\end{array}$ & 1 \\
\hline & $\begin{array}{l}\text { Toba (muestra B4 sitio Grippa 4) } \\
\text { (d) }\end{array}$ & 1 & $\begin{array}{l}\text { Toba (muestras B5 y B7 Manuk } \\
\text { 1) (D) }\end{array}$ & 2 \\
\hline & $\begin{array}{l}\text { Piroclastita (muestra B1sitio } \\
\text { Grippa 5) (g) }\end{array}$ & 1 & $\begin{array}{ll}---- \\
\end{array}$ & 0 \\
\hline \multirow[t]{5}{*}{$\begin{array}{l}\text { Cuenca lagos San } \\
\text { Martín-Tar }\end{array}$} & ---- & 0 & $\begin{array}{l}\text { Basalto microporfírico (taller San } \\
\text { Adolfo) }(\mathbf{C})\end{array}$ & 1 \\
\hline & ---- & 0 & Toba (taller San Adolfo) (D) & 2 \\
\hline & $\begin{array}{ll}---- \\
\end{array}$ & 0 & $\begin{array}{l}\text { Arenisca tufítica (taller San } \\
\text { Adolfo) (E) }\end{array}$ & 1 \\
\hline & ----- & 0 & $\begin{array}{l}\text { Vitrófiro (muestra B13 sitio Los } \\
\text { Bifaces) (I) }\end{array}$ & 1 \\
\hline & $\begin{array}{l}\text { Brecha basáltica (sitio Laguna El } \\
\text { Pajonal) (h) }\end{array}$ & 1 & $\begin{array}{l}---- \\
--\end{array}$ & 0 \\
\hline
\end{tabular}

Si bien las muestras analizadas comparten características macroscópicas, tales como el color negro o gris muy oscuro, existen también diferencias entre ellas. Algunas residen en la formación de pátinas castañas (cuenca Cardiel y mesetas del Strobel y Guitarra) versus gris o negra (cuencas Cardiel y San Martín-Tar, Pampa del Asador, meseta del Águila), la presencia de fenocristales (Pampa del Asador y meseta del Águila) o texturas más (cuencas San Martín-Tar y Cardiel) o menos finas (mesetas del Strobel y Guitarra y cuenca Cardiel) (Tabla 3).

Tabla 3. Características generales de las litologías de las muestras analizadas

\begin{tabular}{|c|c|c|c|c|}
\hline Tipo & Variedades & Color pasta & Color corteza & $\begin{array}{c}\text { Calidad p/ } \\
\text { talla }\end{array}$ \\
\hline Basalto & $\begin{array}{c}\text { Microporfírico, } \\
\text { Olivínico, Piroxénico }\end{array}$ & $\begin{array}{c}\text { Negro, gris oscuro } \\
\text { o claro }\end{array}$ & $\begin{array}{c}\text { Naranja, castaño, } \\
\text { gris, negro }\end{array}$ & Mala a buena \\
\hline Toba & $\begin{array}{c}\text { Intermedia, } \\
\text { Intermedia a ácida }\end{array}$ & Gris oscuro o claro & Naranja, castaño & $\begin{array}{c}\text { Buena a muy } \\
\text { buena }\end{array}$ \\
\hline Piroclastita & - & Gris claro & - & Mala \\
\hline Brecha basáltica & - & Gris oscuro & Gris claro & Buena \\
\hline Arenisca tufítica & Ácida & Gris verdoso o claro & Naranja & Buena \\
\hline Lava vitrofírica & Intermedia & Gris oscuro & Gris claro & Buena \\
\hline Vitrófiro & Intermedio & Negro & - & Muy buena \\
\hline
\end{tabular}

Las muestras de la meseta del Águila (figura 1), corresponden a guijarros naturales que tienen una corteza gris y presencia de fenocristales. Por su parte, en la meseta del Guitarra no se han registrado depósitos de guijarros con calidades óptimas para la talla asignables a basalto, por lo tanto, todas son arqueológicas (sitios CG3 y GUI10). Estas tienen grano fino, pero diferencias 
en la formación de corteza y texturas. En la Pampa del Asador se seleccionaron dos muestras arqueológicas y una geológica de lagunas que se encuentran en el sector sur del Cerro Pampa. Las muestras arqueológicas son lascas registradas en los mismos sectores donde afloran guijarros de basalto. Todas tienen grano fino y corteza gris, no obstante, una muestra arqueológica (B17) tiene escasos fenocristales y una textura más vidriosa que el resto.

La mayoría de las muestras analizadas petrográficamente provienen de la meseta del Strobel, ocho de las cuales son arqueológicas (Sitios K130, K20, K26, K11). Ninguna de las muestras presenta fenocristales y la mayoría tiene grano fino. Se destaca que un $96 \%$ presentan una formación de pátina de color castaña. En función de la consulta a especialistas, estas muestras habían sido clasificadas inicialmente como lutitas. Algunas de estas muestras también tienen una coloración verdosa en la matriz.

En la cuenca Cardiel, las muestras provienen de tres sectores; dos, en margen oeste (sitio arqueológico Manuk 1 y cuenca del arroyo Bayo) y uno, en el este (depósitos próximos al sitio Grippa Si Lito No). Las tres muestras arqueológicas del sitio Manuk 1 tienen grano fino y no presentan fenocristales. Dos de las muestras forman una corteza oxidada o castaña (B2 y B5), mientras que la tercera no tiene corteza, pero su textura es más rugosa (B7). Las dos muestras geológicas de Bayo no presentan fenocristales, una es de un grano muy fino, forma una pátina gris (B3) y la otra es más oscura con una pátina castaña. Las dos muestras de Grippa Si Lito No son de grano fino y no presentan fenocristales, no obstante, una tiene tonos más verdosos y una pátina oscura (B1) y la otra tiene una textura más rugosa (B4).

Finalmente, la mayoría de las muestras de la cuenca de los lagos San Martín-Tar son arqueológicas (sitios San Adolfo y Los Bifaces). Tampoco las muestras de este sector presentan fenocristales. Existen muestras de grano muy fino y textura vidriosa (B13) y muestras con pátinas grises junto con otras más castañas.

\section{Nuevas potenciales fuentes de abastecimiento}

Los relevamientos de campo permitieron reconocer nuevos puntos del paisaje regional con disponibilidad de guijarros, cuya granulometría y color los cataloga inicialmente como basaltos.

Como fuera mencionado, la Pampa del Asador presenta una serie de puntos singulares (cicatrices de erosión, bordes de lagunas, etc.) donde se registran guijarros y bloques de basaltos. En esta oportunidad, se registraron tres nuevos sectores, todos al sudoeste del Cerro Pampa. El primero, es una cicatriz de erosión de $10 \mathrm{~m}$ por $100 \mathrm{~m}$ donde afloran guijarros de dacita, obsidiana negra y basalto con fenocristales. Hay bloques de esta materia prima de unos $25 \mathrm{~cm}$ de largo aproximadamente. Se registran escasos desechos de talla. El segundo conforma un extenso pavimento del desierto sobre la pampa. Aunque la mayoría de los guijarros son de basalto, no todos tienen una buena calidad para la talla y no presentan evidencias de uso. El tercer sector se encuentra en el borde este de una laguna. Consiste en un depósito de guijarros de basalto y escasos de sílices y de dacita. Algunos guijarros tienen alrededor de $20 \mathrm{~cm}$ de largo y presentan fenocristales. El depósito tiene una extensión cercana a 300 m y muy baja frecuencia de desechos de talla y núcleos.

Asimismo, se efectuaron reconocimientos en las pampas intermedias entre la meseta del Asador y la cuenca de los lagos Salitroso-Posadas. Por el momento, en este espacio se registraron dos sectores con guijarros de buena calidad para la talla. El primero es un cauce seco próximo a la estancia La Criolla que acarrea guijarros de diferentes tamaños de basaltos con y sin fenocristales. El segundo es una planicie en la Estancia El Pobre en la cual se registró una serie de bloques y guijarros de basaltos con fenocristales, aproximadamente de $15 \mathrm{~cm}$ de largo y de muy buena calidad para la talla. En ninguno de los dos casos se registraron desechos de talla o núcleos. 
Por su parte, en el sector noreste de la meseta del Strobel, en las márgenes de una laguna se hallaron puntos específicos con escasos clastos de diferentes materias primas. Una fue inicialmente catalogada como basalto y otra como lutita. La roca descripta como basalto se hallaba de manera muy acotada con una dispersión de $4 \mathrm{~m}^{2}$ en la margen sur de la laguna. Los guijarros tienen aproximadamente $10 \mathrm{~cm}$ de largo y su calidad para la talla es regular a buena. Las llamadas lutitas se registraron principalmente en la margen norte de la misma laguna. La extensión del depósito relevado hasta el momento cubre una superficie de $100 \mathrm{~m}$ por $15 \mathrm{~m}$. Los guijarros son angulosos, aproximadamente de $10 \mathrm{~cm}$ de largo con una buena a muy buena calidad para la talla. Algunos se encontraban semienterrados. En ninguno de los dos depósitos se observaron lascas, artefactos formatizados o núcleos.

\section{Análisis petrográfico}

De acuerdo con la caracterización mediante cortes delgados se establece la variabilidad de rocas que macroscópicamente presentan propiedades similares (tabla 2, figura 2). Bajo dicha variabilidad y en términos de la composición, se destacan los basaltos en idéntica frecuencia para muestras arqueológicas y geológicas. Se pudo especificar la presencia de basaltos piroxénicos y olivínicos. Los primeros se forman en la profundidad magmática, mientras que los segundos se caracterizan por una importante porción de hierro y tienen pasta microporfírica. Por otro lado, se encuentran las rocas asignadas como tobas que, en este caso, son rocas intermedias a ácidas, con mayor frecuencia en muestras arqueológicas. Asimismo, tanto en muestras arqueológicas como geológicas, otras rocas se presentan en frecuencias bajas (vitrófiro, arenisca tufítica, brecha o lava). Estas tienen importantes cantidades de sílice y se han formado en diferentes momentos del proceso volcánico. Más allá de la variabilidad en su composición, todas estas rocas poseen textura afanítica, de características vítreas, propiedades que le confieren fractura concoidea, apta para la manufactura de instrumental.

Ahora bien, ¿cómo se distribuye esta variabilidad en términos espaciales? (tabla 2, figura 3). Las dos muestras geológicas de la meseta del Águila han sido catalogadas como basaltos de dos variedades diferentes. Uno, olivínico-piroxénico de textura porfírica y otro, olivínico de textura microporfírica.

En la Pampa del Asador, la muestra geológica ha sido asignada como basalto piroxénico, con textura intersertal. Por su parte, las muestras arqueológicas también son basaltos. Una es un basalto olivínico de textura levemente porfírica y otra, un basalto piroxénico.

Las tres muestras de la meseta del Guitarra tienen leves diferencias macroscópicas. La muestra del sitio CG3 es un basalto piroxénico de textura porfírica. Las dos muestras del sitio GUI10 son las únicas que marcan una variabilidad litológica en todo el sector mesetas del Águila-Guitarra-Pampa del Asador. Una de ellas es asignada como una arenisca tufítica y la otra como una toba de composición intermedia a ácida.

En la meseta del Strobel se analizaron cuatro muestras geológicas. Tres corresponden a los depósitos registrados en las márgenes de una laguna (ver supra). Las rocas asignadas macroscópicamente a basalto son lavas vitrofíricas de composición intermedia con textura afanítica y aquellas clasificadas como lutitas son tobas de composición intermedia a ácida de textura clástica y basalto microporfírico, con pasta vítrea. La cuarta muestra procede del borde sur de la meseta y corresponde a un bloque de basalto olivínico con piroxeno subordinado, con textura porfírica. Por su parte, cinco muestras arqueológicas han sido catalogadas como tobas (tanto de composición intermedia como intermedia a ácida) y dos como basalto microporfírico de base vítrea. La octava muestra ha sido asignada a una arenisca tufítica. 


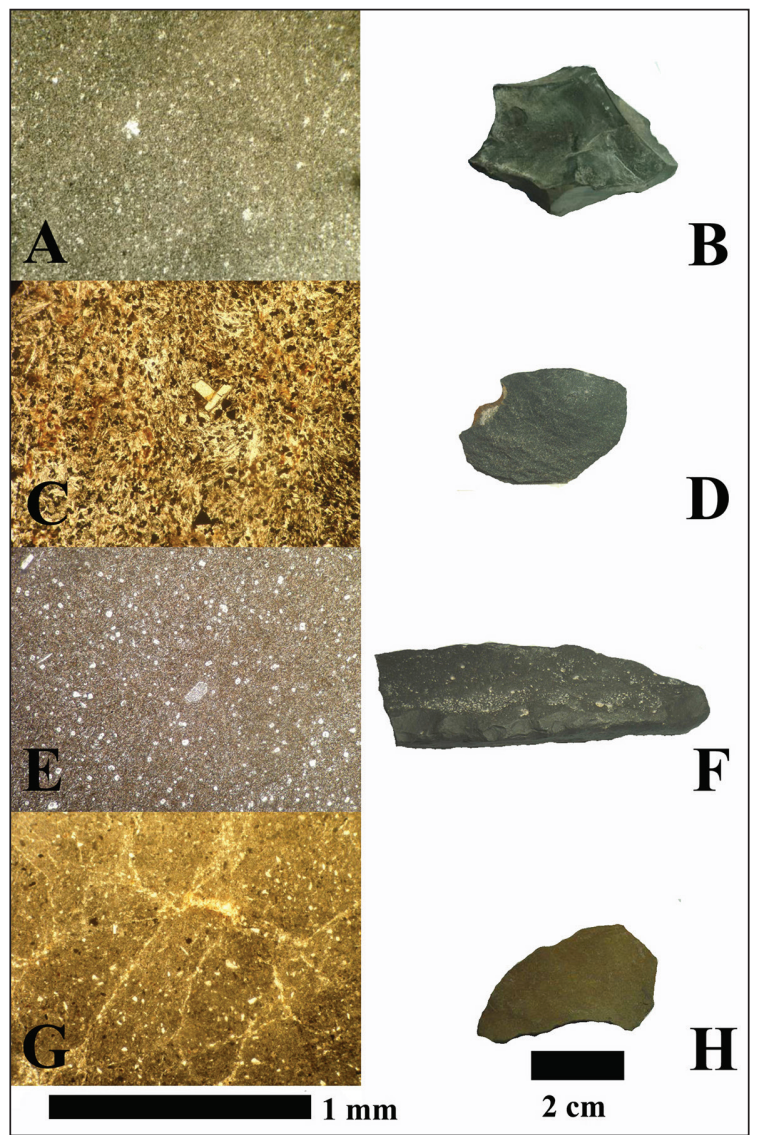

Figura 2. Muestras y cortes delgados. A: corte delgado de lava microporfírica de composición intermedia (Sitio K165, Strobel); B: muestra de lava microporfírica (Sitio K165, Strobel); C: corte delgado de basalto olivínico (laguna al oeste de Cerro Pampa); D: muestra de basalto olivínico (laguna al oeste de Cerro Pampa); E: corte delgado de basalto piroxénico (laguna al oeste de Cerro Pampa); F: muestra de basalto piroxénico (laguna al oeste de Cerro Pampa); G: corte delgado de toba de composición intermedia

(Manuk 1, lago Cardiel); H: muestra de toba de composición intermedia (Manuk 1, lago Cardiel)

En la cuenca Cardiel se seleccionaron cuatro muestras geológicas. En la margen oeste, particularmente en el arroyo Bayo, una es un basalto microporfírico y la otra es un basalto olivínico-piroxénico. En la margen este de la cuenca, la muestra Grippa 5 fue clasificada como una piroclastita y la muestra Grippa 4 fue catalogada como una posible toba de composición intermedia (Agnolin et al. 2018). Las muestras arqueológicas provienen del sitio Manuk 1, al oeste del lago. Estas han sido clasificadas como toba de composición intermedia, posiblemente andesítica (Manuk 1), toba ácida de tipo riolítico a dacítico y basalto piroxénico de textura porfírica.

En la cuenca San Martín-Tar, la muestra geológica de la Laguna El Pajonal ha sido caracterizada como una brecha de composición basáltica de textura tipo clástico. Las muestras arqueológicas provienen de San Adolfo y registran variabilidad en su composición litológica. Dos muestras han sido establecidas como tobas (una, de composición andesítica de textura afanítica y otra, de composición dacítica). Asimismo, se ha registrado una arenisca tufítica o toba de composición ácida de textura clástica y un basalto de textura microporfírica. 


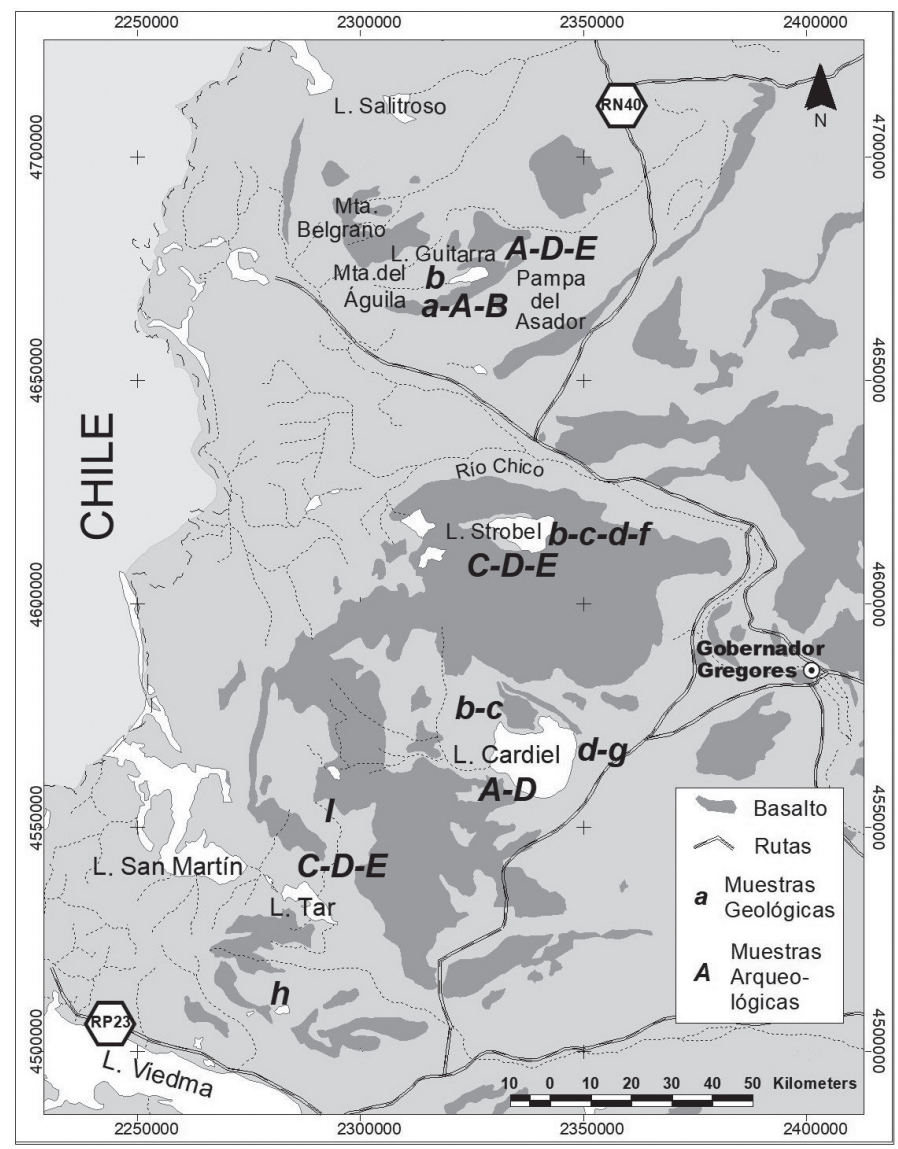

Figura 3. Distribución de mantos basálticos naturales y localización de muestras geológicas (identificadas con letras minúsculas) y muestras arqueológicas (identificadas con letras mayúsculas)

\section{DISCUSIÓN}

La geología del sector cordillerano y pericordillerano de la provincia de Santa Cruz da cuenta de ambientes modelados por glaciares y erupciones volcánicas que generaron una litología compleja. Las investigaciones arqueológicas tendientes a evaluar las estrategias de abastecimiento de recursos líticos desarrolladas por las poblaciones cazadoras-recolectoras han dado cuenta de dicha variabilidad al registrarse no solo la explotación de depósitos de obsidiana negra, limolita y toba silicificada (Espinosa y Goñi 1999; Espinosa et al. 2009; Belardi et al. 2015), sino también de rocas categorizadas macroscópicamente como basalto y una gran variedad de rocas silíceas (Guraieb 2012; Cassiodoro et al. 2015).

Los recientes relevamientos en terreno han permitido registrar nuevos puntos singulares en el espacio que presentan disponibilidad de basaltos de buena calidad para la talla. De este modo, con variaciones internas, cada cuenca presenta disponibilidad local de este recurso. En este contexto debe destacarse que la meseta del Strobel sigue siendo un área con baja disponibilidad de recursos líticos para la talla (Flores Coni 2019). Esto queda evidenciado por la existencia de un único punto en el espacio con guijarros de tobas y basaltos y por la baja frecuencia de núcleos en el registro arqueológico (tabla 1 ). 
En primer lugar, la información proporcionada por los análisis de cortes delgados permite establecer una variabilidad litológica mayor que la inicialmente determinada macroscópicamente. Si bien todas son rocas volcánicas, la misma complejidad de su génesis es la causante de esta diversidad observada. Esta complejidad se manifiesta de manera diferente en cada cuenca.

En la porción norte de la región de estudio, en la zona de la meseta del Águila-GuitarraPampa del Asador, en términos macroscópicos las muestras de basaltos piroxénicos tienen una pasta de grano muy fino, con fenocristales y de tonalidad muy oscura. En el conjunto de artefactos arqueológicos hay piezas con características similares en los sitios de Cerro Pampa y meseta del Strobel. Lo mismo se ha observado respecto de guijarros naturales en puntos singulares de Pampa del Asador y las pampas intermedias entre la meseta del Asador y la cuenca de los lagos Salitroso-Posadas. En términos generales, posee algunas características similares al llamado basalto Posadas, aunque este tiene una granulometría más gruesa y mayor número de fenocristales y de plagioclasas. Las muestras geológicas de la meseta del Águila también tienen características macroscópicas similares al basalto Posadas, pero tienen un mayor componente olivínico que piroxénico. Por lo tanto, estas similitudes macroscópicas y diferencias microscópicas refuerzan la variabilidad dentro de la categoría "basalto Posadas" manifestada en otros trabajos de la región (Belardi y Carballo Marina 2005; Guraieb 2012). Por su parte, los basaltos olivínicos tienen un grano más grueso, no tienen fenocristales y son levemente grisáceos. Se han registrado materiales arqueológicos con estas características en Cerro Pampa y la meseta del Guitarra.

Por lo tanto, este sector norte de la región de estudio, a pesar de estas diferencias en términos macroscópicos y de composición, contiene una efectiva mayoría de muestras de basaltos de disponibilidad local. En principio, las diferencias macroscópicas entre estos dos grandes grupos permitirán efectuar una mejor categorización de todas las muestras arqueológicas del sector. Solo dos muestras arqueológicas de la meseta del Guitarra no pertenecen al grupo de basaltos, sino que se asignan toba y arenisca tufítica. Las diferencias en texturas y coloración de corteza permiten distinguirlas macroscópicamente de los basaltos.

Como fuera mencionado, los nuevos relevamientos en la meseta del Strobel muestran la existencia de un depósito con variedad de tobas, lavas y basaltos. Hasta el momento no se han registrado depósitos con recursos líticos aptos para la manufactura de artefactos. Las muestras geológicas y arqueológicas de este sector dan cuenta de la variabilidad litológica centrada en el basalto y tobas intermedias a ácidas. Estos dos tipos de rocas también presentan diferencias macroscópicas (formación de pátina castaña en tobas) que facilitan la caracterización de los conjuntos arqueológicos. Cabe mencionar, que las particularidades macroscópicas y la asignación petrográfica de las tobas de esta meseta lleva a establecer algún tipo de asociación con las muestras de la meseta del Guitarra.

Por su parte, en la cuenca del lago Cardiel, el arroyo Bayo produce el acarreo de dos tipos distintos de basalto. Uno de grano muy fino (microporfírico) y otro con granos de tamaño intermedio (olivínico/piroxénico). Ninguno presenta fenocristales del estilo Posadas o contenido piroxénico de Pampa del Asador, lo cual permite distinguirlos macroscópicamente. Sin embargo, estos basaltos del arroyo Bayo parecen diferir de la muestra arqueológica de Manuk 1, que es un basalto piroxénico. Este cuarto tipo de basalto también es diferente de las muestras de Pampa del Asador de acuerdo con los estudios de elementos traza (Espinosa et al. 2019).

Particularmente en Manuk 1, hay dos muestras arqueológicas (B5 y B7) que se asignaron como tobas, clasificadas con anterioridad como "basalto de grano fino". Al comparar estas muestras con guijarros naturales recuperados en el arroyo Bayo (sin corte delgado realizado), resultan ser muy similares. Entonces, si se confirmase su identificación, en los depósitos naturales de basalto del arroyo Bayo podría haber también tobas. Estas rocas tienen un grano fino medio, se les genera una pátina castaña, su pasta es gris oscuro y no tienen fenocristales, pero se destacan por "brillos" muy pequeños. Muestras arqueológicas con estas características 
provienen de Manuk 1, del Alero Los Guanacos 1 y la meseta del Strobel. En este sentido, cabe destacar que la muestra B5 de Manuk 1 es una toba intermedia andesítica, al igual que la muestra arqueológica H del Strobel y la geológica B4 de la margen este del lago Cardiel. Por su parte, la muestra B7 de Manuk 1 es más ácida al igual que la toba de la muestra arqueológica B12 de la cuenca San Martín-Tar.

En los médanos de la margen E del lago Cardiel, en Grippa, no habría basaltos tal como fuera propuesto inicialmente (Belardi et al. 2003). Las muestras geológicas informan sobre la disponibilidad de guijarros de toba andesítica y de piroclastita en la margen este de la cuenca. En este caso, las similitudes macroscópicas con los basaltos pueden llevar a dificultades en la clasificación de los conjuntos arqueológicos.

En función de esto, puede plantearse la gran variabilidad y disponibilidad de distintos tipos de basaltos y tobas en la cuenca del lago Cardiel. Por lo tanto, el abastecimiento de materia prima podría haber sido una actividad resuelta en el interior de esta cuenca (Agnolin et al. 2018). A su vez, es factible establecer algún tipo de vinculación con la meseta del Strobel y la cuenca San Martín-Tar. Conclusiones similares surgen del análisis de elementos traza de muestras de basalto (Espinosa et al. 2019).

En la cuenca lacustre San Martín-Tar, cuya litología es más diversa respecto de las demás y la accesibilidad es buena/muy buena, recientemente se han registrado puntos singulares de disponibilidad de basaltos. Esto refuerza lo postulado sobre el aprovisionamiento oportunístico, ya que las actividades de manufactura se limitan a los espacios donde se registraron las dos canteras taller de la cuenca (Espinosa y Belardi 2016). Los cortes delgados dan cuenta de rocas propias de la Formación El Quemado -toba andesítica, dacítica y arenisca tufítica- (Fossa Manzini et al. 1938). Esta Formación se encuentra en espacios occidentales de la cuenca, guijarros de esta pudieron haber sido transportados, mezclados y depositados más al oriente por los procesos fluvioglaciales. Actualmente, algunos de dichos guijarros están disponibles en las laderas de las mesetas basálticas, en donde se encuentran los sitios arqueológicos. Así, esta cuenca también tendría una disponibilidad local de recursos que habría sido utilizada por las poblaciones cazadoras-recolectoras.

Sobre la base de los datos reseñados, se postula la utilización de los basaltos inmediatamente disponibles en Pampa del Asador-meseta del lago Guitarra, cuencas Cardiel y San Martín-Tar. En primer lugar, cada uno de estos sectores posee una señal propia de basalto, la que estaría representada en los correspondientes sitios arqueológicos (tabla 2). Arqueológicamente, la meseta del Strobel presenta mayor variabilidad litológica y menor disponibilidad natural de recursos líticos. En este sentido, esta información contribuye a la propuesta de esta meseta como un espacio de convergencia poblacional, dado que los análisis geoquímicos previos y los aportados en este trabajo apuntarían al ingreso de basaltos y tobas tanto desde los sectores ubicados al norte como desde el sur (Belardi y Goñi 2006; Flores Coni 2019; Espinosa et al. 2019).

En términos generales, puede plantearse que el basalto es la única materia prima de toda la macrorregión que es abundante, está disponible en guijarros medianos a grandes y es de muy buena calidad para la talla. Esta disponibilidad no está sujeta a la presencia natural en las mesetas basálticas que cubren las cotas altas; por el contrario, el aprovisionamiento es factible en todas las cotas estudiadas, lo cual habría permitido su uso sin restricciones a lo largo de las secuencias de ocupación. En este sentido, la disponibilidad es una suerte de constante, por lo cual resulta relevante estudiar la variabilidad de su uso entre las cuencas; podría evaluarse, en consecuencia, cuál ha sido la incidencia de otros factores tales como funcionalidad de sitios, movilidad, cambios temporales, modos de hacer las cosas, etc.

Por otro lado, a partir de estos análisis petrográficos se ha establecido también la disponibilidad natural y utilización de distintas variedades de toba. Esto resulta un aporte al conocimiento de la base de recursos líticos de la región de estudio, ya que se ha dado cuenta de potenciales 
puntos singulares de disponibilidad de estas rocas en las cuencas del Cardiel, San Martín-Tar y tal vez Strobel. Asimismo, estas rocas han sido utilizadas no solo en estas cuencas, sino también en la meseta del Guitarra. Por otra parte, y como fruto de estos análisis, la lutita, categorizada de manera previa y macroscópica como un tipo de roca presente en los conjuntos arqueológicos, ha resultado ser una toba en términos microscópicos. Por consiguiente, la lutita debe descartarse como roca explotada por las poblaciones locales.

Si bien existen diferencias de composición entre tobas, basaltos, areniscas tufíticas, lavas, etc., todas resultan materias primas de muy buena calidad para la talla y han sido utilizadas por las poblaciones cazadoras-recolectoras de la región. Asimismo, comparten propiedades físico-mecánicas por las cuales pueden ser seleccionadas para la manufactura de determinados artefactos que requieran mayor resistencia al momento de uso. En este sentido, hay una tendencia, ya observada con anterioridad, en la selección de basaltos para la manufactura de filos largos, dentro de los conjuntos de la región (Guraieb 1998; Espinosa 2002; Cassiodoro 2011, Espinosa et al. 2017). De esta manera, no solo la forma en que se presenta la materia prima es un atributo de primer orden en el análisis del uso y circulación de rocas en el pasado, sino también las propiedades para la talla y los modos de acción específicos (Ratto 1991) intervienen en la selección de las materias primas.

La región tiene una alta disponibilidad de recursos minerales y se evidencia claramente su utilización. Es decir, el aprovisionamiento de los recursos líticos parece no haber sido un problema para los grupos cazadores-recolectores. Por el contrario, se observa una selección en las rocas utilizadas como materias primas, dentro de la amplia variedad y disponibilidad natural. A su vez, esta disponibilidad es más amplia que la conocida hasta el momento y no se encuentra circunscripta a determinados espacios (por ejemplo, las cotas altas donde se encuentran las mesetas basálticas). Tampoco las fluctuaciones climáticas del Holoceno afectaron el aprovisionamiento de este conjunto de rocas oscuras. Así, se reconoce el amplio conocimiento de la base regional de recursos por parte de las poblaciones y la planificación en su uso.

\section{CONSIDERACIONES FINALES}

Las investigaciones arqueológicas que se vienen desarrollando desde hace más de 25 años en las cuencas lacustres cordilleranas y pericordilleranas de la provincia de Santa Cruz han permitido tener un conocimiento amplio de la base regional de recursos líticos. Este trabajo ha presentado los primeros resultados sobre determinaciones petrográficas planteadas en una escala regional amplia. En esta oportunidad se evaluó la variabilidad geológica y arqueológica de rocas asignadas macroscópicamente como basaltos. Ambas resultan más heterogéneas que lo inicialmente planteado, aportando a una mejor clasificación de las rocas.

Por otra parte, si bien las características geológicas indican la presencia de mantos basálticos en cotas altas, es factible localizar fuentes de aprovisionamiento aún en los sectores bajos. La ubicación, localización y determinación de puntos singulares de disponibilidad de basaltos y tobas pueden utilizarse como indicadores para establecer posibles rutas de circulación. En esa línea, reconocer la dispersión y el grado de intensidad de uso de estas materias primas en cada sector permitirá evaluar la reducida circulación establecida para ellas.

Este trabajo destaca además la importancia de este tipo de análisis que permiten distinguir variedades dentro de grupos de materias primas. A partir de un estudio como este se puede discutir con mayor grado de detalle las estrategias llevadas a cabo por los grupos cazadores así como profundizar en investigaciones centradas en el aprovisionamiento de recursos. 


\section{AGRADECIMIENTOS}

Esta investigación se ha realizado gracias al financiamiento del PIP CONICET 0442, 0418, 406CO, PICT 2013-1965, PI UNPA29/A245, UBACyT 20020130100293BA. Agradecemos la colaboración desinteresada de Cielos Patagónicos y Goldcorp. Un agradecimiento especial por el acompañamiento y colaboración en el campo de Marta Martínez y Chali Oliverio de Estancia Cerro Pampa y a la familia Nuevo Freire y Celso Lillio de la Estancia Las Tunas. A los Dres. Goñi y Belardi y a sus respectivos equipos por colaborar en las tareas de campo. A los revisores anónimos que colaboraron en mejorar la presentación de la información y el alcance de los resultados.

\section{NOTA}

1 La expresión "punto singular" refiere a lugares específicos y poco extensos donde hay concentración de guijarros de buena calidad para la talla (Espinosa et al. 2020).

\section{BIBLIOGRAFÍA}

Agnolin, A.

2019. Aspectos tecnológicos del registro arqueológico de la cuenca del Lago Cardiel y su relación con los cambios climático/ambientales del Holoceno. Tesis Doctoral inédita, Facultad de Filosofía y Letras, Universidad de Buenos Aires.

Agnolin, A., G. Cassiodoro y S. Espinosa

2018. Recursos líticos de la cuenca del lago Cardiel (Santa Cruz): nuevas prospecciones e implicancias para la arqueología regional. Relaciones de la Sociedad Argentina de Antropología XLIII (1): $135-150$.

Andrefsky, W.

1994. Raw material availability and the organization of technology. American Antiquity 59 (1): 21-34.

Aschero, C., C. Bellelli, M. T. Civalero, R. Goñi, A. G. Guráieb y R. Molinari

1992. Cronología y tecnología en el Parque Nacional Perito Moreno (PNPM): continuidad o reemplazos? Arqueología 2: 89-109.

Aschero, C., R. Goñi, M. T. Civalero, R. Molinari, S. Espinosa, A. G. Guraieb y C. Bellelli 2005. Holocenic Park: Arqueología del Parque Nacional Perito Moreno(PNPM). Anales de laAdministración de Parques Nacionales XVII: 71-119.

Bamforth, D.

1986. Technological Efficiency and Tool Curation. American Antiquity 51(1): 38-50.

1990. Settlement, raw material and lithic procurement in the Central Mojave Desert. Journal of Anthropological Archaeology 9: 70-104.

Bamonte, F. P, M. V. Mancini, J. B. Belardi y S. Espinosa

2013. Inferencias paleoambientales a partir del análisis polínico de sitios arqueológicos del área del lago San Martín (Santa Cruz, Argentina). Magallania 41 (1): 155-169.

Beck, C., A. Taylor, G. Jones, C. Fadem, C. Cook y S. Millward

2002. Rocks are Heavy: Transport Costs and Paleoarchaic Quarry Behavior in the Great Basin. Journal of Anthropological Archaeology 21: 481-507. 
Belardi, J. B., G. Barrientos, F. Bamonte, S. Espinosa y R. Goñi

2013. Paleoambientes y cronología de las ocupaciones cazadoras recolectoras de las cuencas de los lagos Tar y San Martín (provincia de Santa Cruz). Intersecciones en Antropología 14: 459-475.

Belardi, J. B. y F. Carballo Marina

2005. Canteras taller de basalto en la zona de Bajo Caracoles-río Olnie (Provincia de Santa Cruz)* Intersecciones en Antropología 6: 223-226.

Belardi, J. B., G. Cassiodoro, R. Goñi, M. Glascock y A. Súnico

2015. Limolites from southern Patagonia (Argentina): their source and archaeological artifact distributions. Geoarchaeology: An International Journal 30: 223-237.

Belardi, J. B. y R. A. Goñi

2006. Representaciones rupestres y convergencia poblacional durante momentos tardíos en Santa Cruz (Patagonia Argentina). El caso de la meseta del Strobel. En D. Fiore y M. M. Podestá (eds.), Tramas en la Piedra: 85-94. Buenos Aires, WAC, SAA y AINA.

Belardi, J. B., R. Goñi, T. Bourlot y A. Aragone

2003. Paisajes arqueológicos en la cuenca del Lago Cardiel (Provincia de Santa Cruz, Argentina). Magallania 31: 95-106.

Cassiodoro, G.

2011. Movilidad y uso del espacio de cazadores-recolectores del Holoceno tardío. Estudio de la variabilidad del registro tecnológico en distintos ambientes del noroeste de la provincia de Santa Cruz (Argentina). BAR International Series 2259.

Cassiodoro, G., S. Espinosa, J. Flores Coni y R. Goñi

2015. Disponibilidad de recursos líticos y movilidad durante el Holoceno tardío en el centro-oeste de la provincia de Santa Cruz. Revista Intersecciones en Antropología. Volumen especial 2: 75-86.

Cassiodoro, G., G. Guráieb, A. Re y A. Tívoli

2004. Distribución de recursos líticos en sitios de superficie de la cuenca de los lagos Pueyrredón-Posadas-

Salitroso. En T. Civalero, P. Fernández y G. Guraieb (comps.), Contra Viento y Marea. Arqueología de Patagonia: 57-69. Buenos Aires, INAPL-SAA.

Cassiodoro, G., D. Rindel, R. Goñi, A. Re, A. Tessone, S. García Guraieb, J. Belardi, S. Espinosa, A. Nuevo Delaunay, J. Dellepiane, J. Flores Coni, F. Guichón, C. Martínez y S. Pasqualini

2013. Arqueología del Holoceno medio y tardío en Patagonia meridional: poblamiento humano y fluctuaciones climáticas. Revista Dialogo Andino 41: 5-23.

Civalero, M. T.

1999. Obsidiana en Santa Cruz, una problemática a resolver. En Soplando en el Viento. Actas de las III Jornadas de Arqueología de la Patagonia: 155-164. Neuquén, Instituto Nacional de Antropología y Pensamiento Latinoamericano y Universidad Nacional del Comahue.

Delcourt, P. y H. Delcourt

1992. Ecotone Dynamics in Space and Time. En A. Hansen y F. Castri (eds.), Landscapes Boundaries. Consequencies for Biotic Diversity and Ecological Flows: 19-54. New York, Springer-Verlag.

Dincauze, D.

1987. Strategies for Paleoenvironmental Reconstruction in Archaeology. Advances in Archaeological Method and Theory 11: 255-296. 
Ericson, J.

1984. Toward the analysis of lithic production systems. En J. Ericson y B. Purdy (eds.), Prehistoric Quarries and Lithic Production: 1-9. Cambridge, Cambridge University Press.

Espinosa, S.

2002. Estrategias tecnológicas líticas y uso del espacio en momentos tardíos en el Parque Nacional Perito Moreno (Santa Cruz). Tesis Doctoral inédita, Facultad de Filosofía y Letras, Universidad de Buenos Aires.

Espinosa, S. y J. Belardi

2016. ¿Eslabones sueltos o cadena en grandes espacios? La ruta del basalto en la cuenca de los lagos Tar y San Martín (Santa Cruz, Argentina). En F. Mena (ed.), Arqueología de la Patagonia: de mar a mar: 179-188. Coyhaique, Ediciones CIEP, Nire Negro Ediciones.

Espinosa, S., J. Belardi, G. Barrientos, P. Campan y A. Súnico

2015. Disponibilidad, circulación y uso de materias primas líticas en las cuencas de los lagos Tar y San Martín (provincia de Santa Cruz, Argentina). Intersecciones en Antropología. Volumen Especial 2: 101-112.

Espinosa, S., J. B. Belardi y A. Súnico

2009. ¿Cuán al oeste? Arqueología del istmo de la península Maipú (lago San Martín, provincia de Santa Cruz) en su contexto regional. Arqueología 15: 187-207.

Espinosa, S., G. Cassiodoro, A. Agnolin y J. Flores Coni

2017. To what extent do raw material or design travel? Distribution of artifacts in central-western Santa Cruz province (Patagonia, Argentina). Trabajo presentado en el $11^{\text {th }}$ International Symposium of Knappable Materials. Buenos Aires, Argentina.

Espinosa, S., G. Cassiodoro, P. Tiberi, J. Flores Coni, A. Nuevo Delaunay y A. Agnolin

2016. Recursos minerales, usos tecnológicos y poblamiento cazador-recolector en Patagonia cordillerana y pericordillerana meridional. Actas del XIX Congreso Nacional de Arqueología Argentina: 14141420. Tucumán.

Espinosa, S. y R. Goñi

1999. Viven! Una fuente de obsidiana en la Pcia. de Santa Cruz. En Soplando en el Viento. Actas de las III Jornadas de Arqueología de la Patagonia: 177-188. Neuquén, Instituto Nacional de Antropología y Pensamiento Latinoamericano y Universidad Nacional del Comahue.

Espinosa, S., P. Tiberi, G. Cassiodoro, A. Agnolin, J. Flores Coni, A. Nuevo Delaunay y C. Stern

2020. Recursos minerales, arqueología y geología en el centro-oeste de Santa Cruz. En Actualización de las investigaciones realizadas en Patrimonio Cultural en Santa Cruz. Santa Cruz, Secretaría de Estado de Cultura de la provincia de Santa Cruz.

Espinosa, S., P. Tiberi, Ch. Stern, G. Cassiodoro, J. Flores Coni y A. Agnolin

2019. Elementos traza en basaltos de la cordillera y precordillera de Santa Cruz (Argentina). Su aplicación en localización de canteras arqueológicas. En J. Goméz Otero, A. Svodoba y A. Banegas (eds.), Arqueología de Patagonia. El pasado en las arenas: 609-622. Puerto Madryn, Instituto de Diversidad y Evolución Austral.

Flores Coni, J.

2018. Poblamiento humano y uso del espacio en la meseta del Strobel (provincia de Santa Cruz). Un análisis sobre la variabilidad tecnológica durante el Holoceno. Tesis Doctoral inédita, Facultad de Filosofía y Letras, Universidad de Buenos Aires.

2019. Population convergence in the Strobel Plateau: A discussion based on the study of lithic raw materials variability. Journal of Archaeological Science: Reports 24: 473-485. 
Fossa Manzini, E., E. Feruglio y A. Yussen de Campana

1938. Una reunión de Geólogos de YPF y el problema de la nomenclatura estratigráfica. Boletín de Informaciones Petrolíferas 171: 31-95.

Gilli, A., F. Anselmetti, D. Ariztegui, J. Bradbury, K. Kelts, V. Markgraf y J. Mckenzie

2001. Tracking abrupt climate change in the Southern Hemisphere: a seismic stratigraphic study of Lago Cardiel, Argentina (49º). Terra Nova 13 (6): 443-448.

González, M.

1992. Paleoambientes del Pleistoceno Tardío/Holoceno Temprano en la cuenca de los lagos Belgrano y Burmeister $\left(47^{\circ} 40^{\prime} / 48^{\circ}\right.$ Sur, $72^{\circ} 30^{\prime}$ Oeste. Santa Cruz). Informe Técnico $\mathrm{N}^{\circ}$ 9:1-7. Fundación C. Caldenius.

Goñi, R.

2000. Arqueología de momentos históricos fuera de los centros de conquista y colonización: un análisis de caso en el sur de la Patagonia. En Desde el País de los Gigantes. Perspectivas Arqueológicas en Patagonia: 283-296. Río Gallegos, UNPA.

2010. Cambio climático y poblamiento humano durante el Holoceno tardío en Patagonia meridional. Una perspectiva arqueológica. Tesis Doctoral inédita. Facultad de Filosofía y Letras, Universidad de Buenos Aires, Buenos Aires.

Gorring, M., S. Mahlburg Kay, P. Zeitler, V. Ramos, D. Rubiolo, M. Fernández y J. Panza

1997. Neogene Patagonian plateau lavas: continental magmas associated with ridge collision at the Chile Triple Junction. Tectonics 16 (1): 1-17.

Guraieb, G.

1998. Cuáles, cuánto y de dónde: tendencias temporales de selección de recursos líticos en Cerro de los Indios I (Lago Posadas, Santa Cruz). Arqueología 8: 77-99.

2012. Tendencias tecnológicas y de diseño de artefactos líticos de las ocupaciones del Holoceno Tardío de Cerro de los Indios 1 (CI1), lago Posadas, provincia de Santa Cruz. Tesis Doctoral inédita. Facultad de Filosofía y Letras, Universidad de Buenos Aires.

Guraieb, G., G. Cassiodoro, A. Re y A. Tivoli

2006. Distancia a la fuente de aprovisionamiento y variabilidad en los conjuntos líticos de la cuenca de los lagos Pueyrredón-Posadas-Salitroso (Patagonia cordillerana argentina). En G. Martínez Fernández, A Morgado Rodríguez y J. Afonso Marrero (eds.), Sociedades prehistóricas, recursos abióticos y territorio. Actas de la III Reunión de trabajo sobre Aprovisionamiento de Recursos Abióticos en la Prehistoria: 199-214. Granada, Fundación Ibn Al Jatib.

Horta, L., S. Georgieff, C. Aschero y R. Goñi

2017. Paleolacustrine Records from Late Pleistocene and Holocene in the Perito Moreno National Park, Argentinian Patagonian Andes. Quaternary International 436: 1-8.

Horta, L., M. Marcos, M. Sacchi, D. Bozzuto, S. Georgieff, M. Mancinic y M. Civalero

2019. Paleogeographic and paleoenvironmental evolution in northwestern Santa Cruz (Argentina), and its influence on human occupational dynamics during the late Pleistocene- early Holocene. Paleogeography, Paleoclimatology, Paleoecology 516: 44-53.

Méndez, C., J. Blanco y C. Quemada

2004. Selección de matrices e intensidad de uso - reavivado en los raspadores (katu) del valle del Chacabuco (transecta occidental de Patagonia Central). Chungara 36: 37-47.

Nami, $\mathrm{H}$.

1992. El subsistema tecnológico de la confección de instrumentos líticos y la explotación de los recursos del ambiente: una nueva vía de aproximación. Shincal 2: 33-53. 
Quade, J. y M. R. Kaplan

2017. Lake-level stratigraphy and geochronology revisited at Lago (Lake) Cardiel, Argentina, and changes in the Southern Hemispheric Westerlies over the last 25 ka. Quaternary Science Reviews 177: 173-188.

Ramos, V.

1982. Descripción geológica de las hojas 53a - Monte San Lorenzo y 53b- Monte Belgrano, Prov. de Santa Cruz. Informe inédito. Servicio Geológico Nacional, Ms.

1999. Los depósitos terciarios sinorogénicos de la región Andina. Anales de Geología Argentina, Instituto de Geología y Recursos Minerales 29(22): 651-682.

Ramos, V. y S. Mahlburg Kay

1992. Southern Patagonian plateau basalts and deformation: backarc testimony of ridge collisions. Tectonophisics 205: 261-282.

Ratto, N.

1991. Elección de rocas y diseño de artefactos: propiedades físico-químicas de las materias primas líticas de Inca Cueva 4 (Jujuy, Argentina). Actas XI Congreso Nacional de Arqueología Chilena. Vol. II: 121-137, Santiago, Chile.

Riccardi, A.

1971. Estratigrafía en el oriente de la Bahía de la Lancha, Lago San Martín, Santa Cruz, Argentina. Revista Museo de la Plata. Geología. VII. 245-238.

Sacchi, M., D. Bozzuto, G. Guraieb, T. Civalero y N. Maveroff

2018. Andesite and obsidian accessibility and distribution during the Holocene in north-west Santa Cruz province (south-central Patagonia), Argentina. Journal of Lithic Studies vol. 5, DOI: https:// doi.org/10.2218/j1s

Stine, $S$.

1994. Extreme and persistent drought in California and Patagonia during mediaeval time. Nature 369: 546-549.

Stine, S. y M. Stine

1990. A record from Lake Cardiel of Climate Change in Southern America. Nature 345: 705-708.

Thacker, P.

2006. Local raw material explotation and prehistoric hunter gatherer mobility. En F. Sellet, R. Greves y P. Yu (eds.), Archaeology and Etnoarchaeology of Mobility: 241-261. Florida, University Press of Florida. 
